\title{
Acute Hemodynamic Effects of Nifedipine in Infants with Bronchopulmonary Dysplasia and Pulmonary Hypertension
}

\author{
JOHN R. BROWNLEE, ROBERT H. BEEKMAN, AND AMNON ROSENTHAL \\ Division of Pediatric Cardiology, C.S. Mott Children's Hospital, University of Michigan, \\ Ann Arbor, Michigan 48109
}

\begin{abstract}
The acute hemodynamic effects of nifedipine were evaluated and compared to the effects of $95 \%$ oxygen in six children with bronchopulmonary dysplasia and pulmonary artery hypertension. The children ranged in age from 7-26 months and all were oxygen dependent. In the cardiac catheterization laboratory, hemodynamic data were collected in $95 \%$ oxygen, room air, and 15 and 30 min after nifedipine administration $(0.5-0.6 \mathrm{mg} / \mathrm{kg}$ per nasogastric tube). Compared to values in room air, nifedipine resulted in a $34 \%$ decrease in pulmonary artery mean pressure (from $69.3 \pm 2.4$ to $45.8 \pm 1.2 \mathrm{~mm} \mathrm{Hg}, p=0.03$ ) and a $49 \%$ decrease in pulmonary vascular resistance (from 14.8 \pm 1.4 to $7.5 \pm 0.9 \mathrm{U} / \mathrm{m}^{2}, p=0.03$ ). A linear relationship was found between the arterial $\mathrm{pO}_{2}$ and the change in the ratio of pulmonary to systemic resistance after nifedipine $\left(\%\right.$ decrease in $\mathrm{Rp} / \mathrm{Rs}$ ratio $=86.3-1.3 \times \mathrm{pO}_{2}, r=-0.95$, $p=0.004$ ) suggesting that nifedipine may act to oppose the vascular effects of arterial hypoxemia. There was no significant change in heart rate, arterial $\mathrm{pO}_{2}$, or $\mathrm{pCO}_{2}$ with nifedipine, but cardiac output increased significantly. Compared to $95 \%$ oxygen, nifedipine achieved a lower pulmonary vascular resistance $(7.5 \pm 0.9$ versus $10.9 \pm 1.2 \mathrm{U} /$ $\left.\mathrm{m}^{2}, p=0.03\right)$ and a greater cardiac output $(5.25 \pm 0.71$ versus $\left.3.54 \pm 0.35 \mathrm{liter} / \mathrm{min} / \mathrm{m}^{2}, p=0.03\right)$ with comparable systemic oxygen delivery $(699 \pm 85 \mathrm{ml}$ versus $698 \pm 91 \mathrm{ml}$ $\mathrm{O}_{2} / \mathrm{min} / \mathrm{m}^{2}, p=1.0$ ). Thus, nifedipine is an acute pulmonary vasodilator in some children with bronchopulmonary dysplasia. Should future studies document that these acute effects are sustained and that long-term administration in childhood is safe, nifedipine may prove valuable in the management of infants with bronchopulmonary dysplasia and pulmonary artery hypertension. (Pediatr Res 24: 186190,1988
\end{abstract}

Abbreviation

BPD, bronchopulmonary dysplasia

Pulmonary artery hypertension may occur in children with BPD and has been shown to be associated with an increase in morbidity and mortality (1). In BPD, pulmonary hypertension appears to reflect the combined effects of hypoxic pulmonary vasoconstriction and structural remodeling of the pulmonary vascular bed (2-6). Recent investigations have demonstrated that administration of high concentrations of inspired oxygen may

Received January 12, 1988; accepted March 29, 1988. Reprint requests Robert H. Beekman, M.D., Division of Pediatric Cardiology, Box 0204, F1116, Mot Children's Hospital, Ann Arbor, MI 48109. Supported in part by NIH General Clinical Research Center Grant 5M01-RR00042. diminish the pulmonary hypertension present in some children with $\operatorname{BPD}(2,3)$. These considerations have prompted us to explore the possibility that a pulmonary vasodilator other than oxygen may provide hemodynamic benefit to children with BPD and pulmonary hypertension.

Nifedipine, an orally administered calcium channel blocker (7), has been found to have beneficial hemodynamic effects in some adults with chronic lung disease and pulmonary artery hypertension. In several studies nifedipine has acutely reduced pulmonary artery pressure and resistance in adults with chronic obstructive pulmonary disease (8-11). Furthermore, nifedipine seems to be especially effective in the presence of hypoxic pulmonary vasoconstriction (10). We therefore initiated a protocol to evaluate the acute hemodynamic effects of nifedipine in infants and children with BPD and pulmonary artery hypertension and to compare these effects to those achieved by administering a high concentration of inspired oxygen. Herein we describe our preliminary findings in the first six children evaluated.

\section{METHODS}

During an 18-month period at C.S. Mott Children's Hospital seven children met entry criteria and participated in this study. Criteria for entrance into this study were: 1) bronchopulmonary dysplasia, evidenced by a history of $\geq 1$ wk of positive pressure ventilation as a newborn, supplemental oxygen dependency beyond 1 month of age, the clinical presence of rales, rhonchi, and tachypnea, and characteristic radiographic findings on chest $\mathrm{x}$ ray $(12) ; 2$ ) right ventricular hypertrophy on electrocardiogram and/or echocardiogram; and 3) absence of structural heart disease. Before entry into this study the clinical management of each child was guided by the referring pediatrician and was not determined by an organized protocol. The nifedipine study protocol was approved by the University of Michigan Institutional Review Board, and informed consent for participation in the study was obtained from each patient's legal guardian.

The acute effects of nifedipine were evaluated in the catheterization laboratory, with each patient lightly sedated with chloral hydrate. After percutaneous entry into the femoral vein and artery, a 5 French thermodilution catheter was used to obtain right heart measurements and a 4-5 French pigtail catheter was used for left heart measurements. A complete right and left heart catheterization was performed, the presence of structural heart disease excluded, and pulmonary hypertension (mean pressure $>25 \mathrm{~mm} \mathrm{Hg}$ ) confirmed. A 5-month-old girl was found to have a mean pulmonary artery pressure of $22 \mathrm{~mm} \mathrm{Hg}$ and was therefore excluded from the nifedipine trial. Hemodynamic measurements made in duplicate included: heart rate; pressure in the aorta, pulmonary artery, pulmonary capillary wedge position and right atrium; oxygen saturation in the aorta, pulmonary artery, and superior vena cava; thermodilution cardiac 
output; and arterial blood gas. The validity of the pulmonary capillary wedge pressure measurement was assured in each subject by comparison to the left ventricular end-diastolic pressure measured simultaneously. Data were collected in the following sequence of conditions: 1) in 95\% oxygen for $45-60 \mathrm{~min} ; 2$ ) in room air for 20-30 min (patients 4 and 6 could tolerate only an $\mathrm{FIO}_{2}$ of 0.30 and 0.25 , respectively); and 3) 15 and 30 min after nifedipine administration (breathing room air).

Nifedipine was withdrawn from a $10 \mathrm{mg}$ capsule (Procardia, $0.34 \mathrm{ml} /$ capsule) using a tuberculin syringe, and was administered through a nasogastric tube. The first two patients received a dose of 1.5 and $1.0 \mathrm{mg} / \mathrm{kg}$, respectively, and had a decrease in aortic mean pressure exceeding $20 \%$; subsequently, the last four patients received a dose of $0.5-0.6 \mathrm{mg} / \mathrm{kg}$ without an untoward effect on systemic arterial pressure.

Values are expressed as the mean \pm 1 SEM. Measured and calculated data are compared using the sign test, a nonparametric test appropriate for a small sample size and not requiring the assumption that data are distributed normally. To avoid the problems associated with multiple testing, comparisons are limited to those between nifedipine and room air and nifedipine and oxygen. Differences are considered statistically significant if $p<0.05$ using a two-tailed test.

\section{RESULTS}

The six children receiving nifedipine ranged in age from 7-26 months and in weight from $3.9-9.5 \mathrm{~kg}$ (Table 1). In room air all six children had significant arterial hypoxemia, their arterial $\mathrm{pO}_{2}$ ranging from $32-52 \mathrm{~mm} \mathrm{Hg}(40 \pm 3.8 \mathrm{~mm} \mathrm{Hg})$. Arterial $\mathrm{pCO}_{2}$ ranged from $32-77(48 \pm 6.4 \mathrm{~mm} \mathrm{Hg})$, and the arterial $\mathrm{pH}$ was normal (mean $7.39 \pm 0.02$ ). Supplemental oxygen had been administered to all patients, four by nasal cannula and two by assisted ventilation, to maintain an arterial oxygen saturation of more than $85 \%$. All children were receiving chronic diuretic therapy, but none was on digoxin. Right ventricular hypertrophy was evident in all six children by electrocardiogram and 2dimensional echocardiogram. One child (case 2) had a history of systemic arterial hypertension of unknown etiology, but none had evidence of left ventricular hypertrophy or dysfunction. Two subjects had undergone ligation of a patent ductus arteriosus; none had a patent ductus at the time of the study.

Pertinent hemodynamic data are presented in Tables 2 and 3. In room air, all six children had severe pulmonary artery hypertension. The mean pulmonary artery pressure for the group was slightly suprasystemic, averaging $69.3 \pm 2.4 \mathrm{~mm} \mathrm{Hg}$ compared to a mean aortic pressure of $66.8 \pm 3.3 \mathrm{~mm} \mathrm{Hg}$. Pulmonary vascular resistance and the ratio of pulmonary to systemic resistance were similarly elevated at $14.8 \pm 1.4 \mathrm{U} / \mathrm{m}^{2}$ and $1.06 \pm 0.10$, respectively. A nearly significant relationship was found between the pulmonary vascular resistance and arterial $\mathrm{pO}_{2}$ (pulmonary vascular resistance $=3.67+0.28 \times \mathrm{pO}_{2}, r=0.77, p=0.07$ ), suggesting that arterial hypoxemia does indeed contribute to the pulmonary hypertension in these children. The cardiac output in room air was normal $\left(4.35 \pm 0.39 \mathrm{liter} / \mathrm{min} / \mathrm{m}^{2}\right)$.

After nifedipine administration pulmonary artery pressure and pulmonary vascular resistance decreased acutely in each patient (Fig. 1). There was no statistical difference in any measurement 15 and $30 \mathrm{~min}$ after nifedipine and therefore the data presented represent the mean of these two measurements. Compared to values in room air, pulmonary artery mean pressure fell by $34 \%$ from $69.3 \pm 2.4$ to $45.8 \pm 1.2 \mathrm{~mm} \mathrm{Hg}(p=0.03)$. Pulmonary vascular resistance decreased by $49 \%$ from $14.8 \pm 1.4$ to $7.5 \pm$ $0.9 \mathrm{U} / \mathrm{m}^{2}(p=0.03)$ whereas systemic vascular resistance did not decrease significantly. Thus, after nifedipine the ratio of pulmonary to systemic resistance diminished from $1.06 \pm 0.10$ to $0.67 \pm 0.04(p=0.03)$. The decrease in the ratio of pulmonary to systemic vascular resistance was found to relate to the degree of arterial hypoxemia. The greatest decrease in the pulmonary to systemic resistance ratio occurred in children whose arterial $\mathrm{pO}_{2}$ in room air was the lowest (\% decrease in ratio of pulmonary

Table 1. Clinical characteristics of 6 children with BPD and pulmonary hypertension who received acute trial of nifedipine*

\begin{tabular}{|c|c|c|c|c|c|c|c|}
\hline \multirow[b]{2}{*}{ Case } & \multirow{2}{*}{$\begin{array}{l}\text { Age } \\
(\mathrm{mo})\end{array}$} & \multirow{2}{*}{$\begin{array}{r}\mathrm{Wt} \\
(\mathrm{kg})\end{array}$} & \multicolumn{2}{|c|}{ Room air } & \multirow[b]{2}{*}{$\mathrm{O}_{2}$ Supplementation } & \multirow[b]{2}{*}{ CTR* } & \multirow[b]{2}{*}{ Medications } \\
\hline & & & $\mathrm{PaO}_{2}$ & $\mathrm{PaCO}_{2}$ & & & \\
\hline 1 & 15 & 4.8 & 52 & 49 & 2 liter $\mathrm{NC} \dagger$ & 0.55 & $\begin{array}{l}\text { Furosemide } \\
\text { Spironolactone }\end{array}$ \\
\hline 2 & 20 & 9.5 & 49 & 49 & 1 liter NC & 0.70 & Furosemide \\
\hline 3 & 7.5 & 4.3 & 32 & 32 & 2 liter $\mathrm{NC}$ & 0.64 & $\begin{array}{l}\text { Chlorothiazide } \\
\text { Spironolactone }\end{array}$ \\
\hline 4 & 8.5 & 5.6 & 42 & 42 & Ventilator & 0.61 & $\begin{array}{l}\text { Furosemide } \\
\text { Chlorothiazide }\end{array}$ \\
\hline 5 & 26 & 8.9 & 29 & 77 & 1 liter $\mathrm{NC}$ & 0.61 & $\begin{array}{l}\text { Furosemide } \\
\text { Spironolactone }\end{array}$ \\
\hline 6 & 7 & 3.9 & 35 & 39 & Ventilator & 0.51 & Chlorothiazide \\
\hline
\end{tabular}

* Abbreviations: CTR, cardiothoracic ratio on chest x-ray; NC, nasal cannula.

Table 2. Effects of nifedipine and 95\% oxygen on pulmonary hemodynamics in 6 children with BPD*

\begin{tabular}{|c|c|c|c|c|c|c|c|c|c|c|c|c|}
\hline \multirow[b]{2}{*}{ Case } & \multicolumn{3}{|c|}{$\mathrm{CI}\left(\right.$ liter $\left./ \mathrm{min} / \mathrm{m}^{2}\right)$} & \multicolumn{3}{|c|}{$\mathrm{PAP}(\mathrm{mm} \mathrm{Hg})$} & \multicolumn{3}{|c|}{$\mathrm{Rp}\left(\mathrm{U} / \mathrm{m}^{2}\right)$} & \multicolumn{3}{|c|}{$\mathrm{Rp} / \mathrm{Rs}$ ratio } \\
\hline & $\mathrm{RA}$ & $\mathrm{N}$ & $\mathrm{O}$ & RA & $\mathrm{N}$ & $\mathrm{O}$ & RA & $\mathrm{N}$ & $\mathrm{O}$ & $\mathrm{RA}$ & $\mathrm{N}$ & $\mathrm{O}$ \\
\hline 1 & 3.31 & 3.67 & 2.72 & 75 & 47 & 40 & 20.8 & 10.4 & 11.4 & 1.06 & 0.81 & 0.40 \\
\hline 2 & 3.67 & 4.24 & 3.46 & 60 & 42 & 40 & 14.4 & 8.0 & 9.2 & 0.70 & 0.58 & 0.39 \\
\hline 3 & 4.79 & 8.43 & 5.03 & 70 & 42 & 45 & 14.9 & 4.1 & 8.3 & 1.46 & 0.75 & 0.71 \\
\hline 4 & 3.59 & 4.09 & 3.04 & 65 & 47 & 53 & 15.6 & 8.8 & 14.1 & 0.96 & 0.64 & 0.69 \\
\hline 5 & 5.56 & 5.87 & 4.05 & 76 & 49 & 46 & 11.2 & 5.9 & 7.9 & 1.11 & 0.58 & 0.59 \\
\hline 6 & 5.17 & 5.18 & 2.94 & 70 & 48 & 50 & 12.0 & 7.6 & 14.3 & 1.07 & 0.66 & 0.66 \\
\hline Mean & 4.35 & 5.25 & 3.54 & 69.3 & 45.8 & 45.7 & 14.8 & 7.5 & 10.9 & 1.06 & 0.67 & 0.57 \\
\hline SEM & 0.39 & 0.71 & 0.35 & 2.4 & 1.2 & 2.1 & 1.4 & 0.9 & 1.2 & 0.10 & 0.04 & 0.06 \\
\hline$p$ value $(v s \mathrm{~N})$ & 0.03 & & 0.03 & 0.03 & & 1.0 & 0.03 & & 0.03 & 0.03 & & 1.0 \\
\hline
\end{tabular}

* Abbreviations: CI, cardiac index; N, nifedipine; O, oxygen; PAP, mean pulmonary artery pressure; RA, room air; Rp, pulmonary vascular resistance; $\mathrm{Rp} / \mathrm{Rs}$, ratio of pulmonary to systemic vascular resistance. 
Table 3. Effects of nifedipine and 95\% oxygen on systemic hemodynamics and oxygen transport in 6 children with BPD*

\begin{tabular}{|c|c|c|c|c|c|c|c|c|c|c|c|c|c|c|c|c|c|c|}
\hline \multirow[b]{2}{*}{ Case } & \multicolumn{3}{|c|}{ Heart rate } & \multicolumn{3}{|c|}{ CI (liter $\left./ \mathrm{min} / \mathrm{m}^{2}\right)$} & \multicolumn{3}{|c|}{$\mathrm{AOP}(\mathrm{mm} \mathrm{Hg})$} & \multicolumn{3}{|c|}{$\operatorname{Rs}\left(U / m^{2}\right)$} & \multicolumn{3}{|c|}{$\begin{array}{c}\text { ART } \mathrm{pO}_{2}(\mathrm{~mm} \\
\mathrm{Hg})\end{array}$} & \multicolumn{3}{|c|}{$\mathrm{SOT}\left(\mathrm{ml} / \mathrm{min} / \mathrm{m}^{2}\right)$} \\
\hline & $\mathrm{RA}$ & $\mathrm{N}$ & $\mathrm{O}$ & $\mathrm{RA}$ & $\mathrm{N}$ & $\mathrm{O}$ & $\mathrm{RA}$ & $\mathrm{N}$ & $\mathrm{O}$ & $\mathrm{RA}$ & $\mathrm{N}$ & $\mathrm{O}$ & $\mathrm{RA}$ & $\mathrm{N}$ & $\mathrm{O}$ & $\mathrm{RA}$ & $\mathrm{N}$ & $\mathrm{O}$ \\
\hline 1 & 115 & 138 & 91 & 3.31 & 3.67 & 2.72 & 72 & 53 & 82 & 19.6 & 12.8 & 28.3 & 52 & & 226 & 443 & & 462 \\
\hline 2 & 116 & 121 & 97 & 3.67 & 4.24 & 3.46 & 79 & 61 & 84 & 20.7 & 13.7 & 23.4 & 49 & 43 & 337 & 797 & 876 & 929 \\
\hline 3 & 162 & 173 & 135 & 4.79 & 8.43 & 5.03 & 55 & 52 & 65 & 10.2 & 5.5 & 11.7 & 32 & 38 & 10 & 476 & 958 & 801 \\
\hline 4 & 122 & 127 & 121 & 3.59 & 4.09 & 3.04 & 65 & 65 & 70 & 16.2 & 13.7 & 20.4 & 42 & 44 & 149 & 396 & 480 & 488 \\
\hline 5 & 130 & 128 & 100 & 5.56 & 5.87 & 4.05 & 65 & 68 & 63 & 10.1 & 10.1 & 13.3 & 29 & 30 & 85 & 563 & 612 & 796 \\
\hline 6 & 115 & 118 & 94 & 5.17 & 5.18 & 2.94 & 65 & 68 & 70 & 11.2 & 11.6 & 21.8 & 35 & 34 & 103 & 567 & 568 & 475 \\
\hline Mean & 127 & 134 & 106 & 4.35 & 5.25 & 3.54 & 66.8 & 61.2 & 72.3 & 14.7 & 11.2 & 19.8 & 40 & 38 & 168 & 540 & 699 & 659 \\
\hline SEM & 7 & 8 & 7 & 0.39 & 0.71 & 0.35 & 3.3 & 2.9 & 3.6 & 2.0 & 1.3 & 2.6 & 4 & 2 & 40 & 58 & 85 & 85 \\
\hline $\begin{array}{l}p \text { value (vs } \\
\mathrm{N} \text { ) }\end{array}$ & 0.23 & & 0.03 & 0.03 & & 0.03 & 1.0 & & 0.23 & 0.38 & & 0.03 & 1.0 & & 0.06 & 0.06 & & 1.0 \\
\hline
\end{tabular}

* Abbreviations: $\mathrm{AOP}$, mean aortic pressure; $\mathrm{ART} \mathrm{pO}_{2}$, arterial $\mathrm{pO}_{2}$; $\overline{\mathrm{CI}}$, cardiac index; $\mathrm{N}$, nifedipine; $\mathrm{O}$, oxygen; $\mathrm{RA}$, room air; Rs, systemic vascular resistance; SOT, systemic oxygen transport.


Fig. 1. The acute effects of nifedipine in six children with BPD and pulmonary artery hypertension. The changes in pulmonary vascular resistance $(R p)$, systemic vascular resistance $(R s)$, and their ratio $(R p /$ $R s)$ are shown.

to systemic vascular resistance $=86.3-1.3 \times \mathrm{pO}_{2}, r=-0.95, p$ $=0.004$, Fig. 2).

After nifedipine administration cardiac output increased (4.35 \pm 0.39 to $5.25 \pm 0.71 \mathrm{liter} / \mathrm{min} / \mathrm{m}^{2}, p=0.03$ ). Heart rate; arterial oxygen saturation; arterial $\mathrm{pO}_{2}, \mathrm{pCO}_{2}$, and $\mathrm{pH}$; and pulmonary artery wedge and right atrial pressure were unaffected by nifedipine. Mixed venous $\mathrm{O}_{2}$ saturation increased from $49 \pm 5$ to 54 $\pm 3 \%$, but did not attain statistical significance $(p=0.23)$. Although aortic mean pressure did not change for the group as a whole, it did decrease modestly in patients 1 and 2 (Table 3). These two patients, the first enrolled in this study, received a nifedipine dose of 1.5 and $1.0 \mathrm{mg} / \mathrm{kg}$; subsequent patients have received $0.5-0.6 \mathrm{mg} / \mathrm{kg}$ without an adverse effect on systemic arterial pressure.



Fig. 2. A significant inverse linear relationship is present between the percent decrease in the ratio of pulmonary to systemic resistance $(R p /$ $R s$ ) after nifedipine administration and the arterial $\mathrm{pO}_{2}$ in room air. Nifedipine produced the greatest vascular effects in children with the most pronounced hypoxemia.

Oxygen is a potent pulmonary vasodilator $(2,3,13)$. However, when data obtained after nifedipine administration are contrasted to those obtained in $95 \%$ oxygen, several differences become apparent (Tables 2 and 3). Compared to oxygen, nifedipine produced a significantly lower pulmonary resistance $(7.5$ \pm 0.9 versus $\left.10.9 \pm 1.2 \mathrm{U} / \mathrm{m}^{2}, p=0.03\right)$ and a greater cardiac output (5.25 \pm 0.71 versus $\left.3.54 \pm 0.35 \mathrm{liter} / \mathrm{min} / \mathrm{m}^{2}, p=0.03\right)$. There was no difference between nifedipine and oxygen in pulmonary artery mean pressure $(45.8 \pm 1.2$ versus $45.7 \pm 2.1 \mathrm{~mm}$ $\mathrm{Hg}, p=1.0)$, the ratio of pulmonary to systemic resistance $(0.67$ \pm 0.04 versus $0.57 \pm 0.06, p=1.0$ ), or aortic mean pressure $(61.2 \pm 2.9$ versus $72.3 \pm 3.6 \mathrm{~mm} \mathrm{Hg}, p=0.23)$. Oxygen did result in a higher systemic resistance $(19.8 \pm 2.6$ versus $11.2 \pm$ $\left.1.3 \mathrm{U} / \mathrm{m}^{2}, p=0.03\right)$, a lower heart rate $(106 \pm 7$ versus $134 \pm 8$ bpm, $p=0.03)$, and a higher arterial $\mathrm{pO}_{2}(168 \pm 40$ versus $38 \pm$ $2, p=0.06)$. Because cardiac output was greater, systemic oxygen transport after nifedipine (the product of cardiac output and arterial oxygen content) was virtually identical to that in $95 \%$ oxygen $\left(699 \pm 85\right.$ versus $\left.698 \pm 91 \mathrm{ml} \mathrm{O} 2 / \mathrm{min} / \mathrm{m}^{2}, p=1.0\right)$.

\section{DISCUSSION}

The findings of this preliminary study demonstrate that nifedipine is an acute pulmonary vasodilator in some children with BPD and pulmonary artery hypertension. In the six children evaluated, pulmonary artery pressure and resistance decreased 
by 34 and $49 \%$, respectively, within 15 min of nifedipine administration. This effect was accomplished without apparent adverse effect on cardiac output, systemic arterial pressure, $\mathrm{pO}_{2}$, or $\mathrm{pCO}_{2}$. The degree of pulmonary hypertension found in these six children was remarkable, and greater on the average than that reported in previous studies $(2,3)$. An explanation for this finding is not clear, but it may relate to the entry criteria used or to the conservative use of supplemental oxygen in four of the six children before entry into the study (cases $1-3,5$ ). These children had received 1-2 liter/min of oxygen by nasal cannula to raise the resting arterial $\mathrm{O}_{2}$ saturation above $85 \%$. Such a relatively low dose of chronic oxygen therapy may have led to increased pulmonary vascular remodeling and affected the level of pulmonary artery hypertension detected in these children during our study.

All six children had an element of reversible pulmonary artery hypertension that was acutely responsive to oxygen or nifedipine. These findings are consistent with the work of Abman et al. (2) who evaluated the effects of supplemental oxygen administration in six children with BPD. An acute beneficial response was noted in all six children, with mean pulmonary artery pressure decreasing by $10 \mathrm{~mm} \mathrm{Hg}$ or more and pulmonary vascular resistance decreasing by an average of $59 \%$. In a similar hemodynamic evaluation of nine children with BPD, Berman et al. (3) found only five responsive to oxygen although three infants had only borderline pulmonary artery hypertension. Two children with substantial elevation of pulmonary artery pressure, however, were unaffected by supplemental oxygen. Thus, although not identified in our study, there may be a subpopulation of children with BPD whose pulmonary hypertension is unresponsive to oxygen.

Kochanek and Zaritsky (14) have reported a child with BPD and pulmonary artery hypertension that was unaffected by oxygen but that decreased substantially after nifedipine administration. Our data also suggest that nifedipine may have hemodynamic advantages over oxygen as a pulmonary vasodilator in this population of children. First, pulmonary vascular resistance was $31 \%$ lower after nifedipine than during administration of $95 \%$ oxygen. Nifedipine may have been a more effective pulmonary vasodilator because it has vascular access to the pulmonary resistance vessels. Oxygen, in contrast, may have limited access to the vasoconstricted segments of pulmonary vasculature in areas of patchy atelectasis and alveolar hypoventilation. Second, the changes in cardiac output induced by nifedipine and oxygen were distinctly different. Cardiac output was $49 \%$ higher after nifedipine than during oxygen administration. High inspired concentrations of oxygen have been shown to depress cardiac output in children by increasing systemic vascular resistance and left ventricular afterload (13). In contrast nifedipine promotes pulmonary and systemic vasodilation, reduces the afterload of both ventricles, and tends to increase cardiac output. These disparate cardiovascular effects explain the finding that oxygen delivery to the tissues was virtually identical with nifedipine or $95 \%$ oxygen, despite the higher arterial oxygen tension during oxygen supplementation.

Nifedipine promotes vasodilation by inhibiting calcium influx through calcium-selective channels in cell membranes, thereby relaxing vascular smooth muscle (7). The observation (Fig. 2) that the changes in vascular resistance with nifedipine relate inversely to the degree of arterial hypoxemia, with greater effects occurring in children with a lower arterial $\mathrm{pO}_{2}$, suggests that nifedipine may be opposing the vascular effects of arterial hypoxemia. Although hypoxemia is a potent pulmonary vasoconstrictor, several studies in addition to ours have shown that nifedipine can counter it's effects $(15,16)$. Kennedy and Summer (15), for example, found that nifedipine reduced hypoxia-induced pulmonary vasoconstriction in a dose-dependent fashion when infused into the pulmonary artery of isolated perfused pig lungs. Furthermore, reports in adults with chronic obstructive lung disease have indicated that nifedipine can diminish hypoxic pulmonary vasoconstriction in many such patients $(8-10)$. Simoneau et al. (10), in a study of 13 adults with acute respiratory failure, demonstrated that the magnitude of reduction in pulmonary artery pressure with nifedipine was directly related to the degree of arterial hypoxemia. No vasodilator, however, can reverse anatomic loss of vessel cross-sectional area resulting from vascular remodeling or the destruction of lung parenchyma. Morphometric analyses of the pulmonary vascular bed have demonstrated such anatomic changes in children with BPD (46). These observations may explain the finding that despite substantial acute hemodynamic improvement neither nifedipine nor oxygen was able to normalize pulmonary artery pressure or resistance in any child in our series.

The use of vasodilator drugs in children with BPD and pulmonary artery hypertension remains under investigation. There are potential adverse effects, both known and unknown, that must be considered before these agents are used clinically. Vasodilators may cause systemic arterial hypotension and tachycardia as well as an increase in the intrapulmonary right to left shunt (10), all of which would be poorly tolerated in an infant with severe BPD. Further, calcium channel blocking agents may exert a negative inotropic effect (7) that would be undesirable in children with right or left ventricular dysfunction. For these reasons we recommend that the acute effects of vasodilator agents be assessed in each child in the cardiac catheterization laboratory. Finally, the long-term consequences of vasodilator therapy in general, and calcium channel blockade in particular, have not been thoroughly studied in infants and children. Although calcium channel blockers have been used safely in children with hypertrophic cardiomyopathy (17) or muscular dystrophy (18), their safe use in children with BPD has not yet been documented.

In conclusion, nifedipine is an acute pulmonary vasodilator in some children with BPD. Although preliminary in nature, the data suggest that nifedipine may offer hemodynamic advantages to oxygen by reducing pulmonary artery pressure and resistance without the systemic vasoconstriction and depression of cardiac output that occurs during administration of high concentrations of inspired oxygen (13). Long-term reduction of pulmonary artery hypertension may be expected to preserve right ventricular function and to diminish overall morbidity and mortality in children with severe BPD (1-3). However, until additional data are obtained nifedipine must remain an investigational drug for treatment of infants with BPD. Studies are currently underway in our laboratory to define nifedipine absorption and pharmacokinetics as well as long-term tolerance and potential toxicity in this patient population. Should future studies document that the acute hemodynamic benefits are sustained and that longterm administration during childhood is safe, nifedipine therapy may prove valuable in the management of infants with BPD and pulmonary artery hypertension.

\section{REFERENCES}

1. Fouron JC, LeGuenner JC, Villemant D, Bard H, Perrault G, Davignon A 1980 The outcome of bronchopulmonary dysplasia of the newborn. Pediatrics 65:529-535

2. Abman SH, Wolfe RR, Accurso PS, Koops BL, Bowman M, Wiggins JW Jr 1985 Pulmonary vascular response to oxygen in infants with severe bronchopulmonary dysplasia. Pediatrics 75:80-84

3. Berman W Jr. Yabek SM, Dillon T, Burstein R Corlew S 1982 Evaluation of infants with bronchopulmonary dysplasia using cardiac catheterization. Pediatrics 70:708-711

4. Sobonya RE, Logvinoff MM, Taussig LM, Theriaut A 1982 Morphometric analysis of the lung in prolonged bronchopulmonary dysplasia. Pediatr Res 16:969-972

5. Bonikos DS, Klaus GB, Northway WH Jr, Edwards DK 1976 Bronchopulmonary dysplasia: The pulmonary pathologic sequelae of necrotizing bronchitis and pulmonary fibrosis. Hum Pathol 6:643-666

6. Stocker JT 1986 Pathologic features of long-standing "healed" bronchopulmonary dysplasia: a study of 283 - to 40 -month old infants. Hum Pathol 17:943-961

7. Katz AM, Hager WD, Messino FC, Pappano AJ 1984 Cellular actions and pharmacology of the calcium channel blocking drugs. Am J Med 77:2-10

8. Kennedy TP, Micheal JR, Huang C-H, Kallman CH, Zahka K, Schlott W, Summer W 1984 Nifedipine inhibits hypoxic pulmonary vasoconstriction 
during rest and exercise in patients with chronic obstructive pulmonary disease. Am Rev Respir Dis 129:544-551

9. Muramoto A, Caldwell J, Albert RK, Kasgminarayan S, Butler J 1981 Nifedipine reduces pulmonary artery pressure at comparable cardiac output in patients with chronic obstructive pulmonary disease. Circulation 64:IV179(abstr)

10. Simoneau G, Escourrou P, Duroux P, Lockhart A 1981 Inhibition of hypoxic pulmonary vasoconstriction by nifedipine. N Engl J Med 304:1582-1585

11. Hohnloser S, Bonzel T, Wollschlager H, Zeither A, Lollgen H, Just H 1984 Nifedipine therapy for pulmonary hypertension-acute and long term effects. J Am Coll Cardiol 3:578(abstr)

12. Harrod JR, L'Heureux P, Wagensteen OD, Hunt CE 1974 Long term followup of severe respiratory distress syndrome treated with IPPB. J Pediatr 84:277-286

13. Beekman RH, Rocchini A, Rosenthal A 1983 Cardiovascular effects of breath- ing $95 \%$ oxygen in children with congenital heart disease. Am J Cardiol 52:106-111

14. Kochanek P, Zaritsky A 1986 Nifedipine in the treatment of a child with pulmonary hypertension associated with severe bronchopulmonary dysplasia. Clin Pediatr (Phila) 25:214-216

15. Kennedy T, Summer W 1982 Inhibition of hypoxic pulmonary vasoconstriction by nifedipine. Am J Cardiol 50:864-868

16. Philips JB, Lyrene RK, Leslie GI, McDevitt M, Cassady G 1982 Cardiopulmonary effects of nifedipine in normoxic and hypoxic newborn lambs. Circulation 66:II-111(abstr)

17. Spicer RL, Rocchini AP, Crowley DC, Rosenthal A 1984 Chronic verapamil therapy in pediatric and young adult patients with hypertrophic cardiomyopathy. Am J Cardiol 53:1614-1619

18. Moxley RT 1985 Absence of major side effects of nifedipine following treatment of Duchenne dystrophy. Pediatrics 75:1168-1169 